Hydrological Research Letters 7(3), 60-65 (2013)

Published online in J-STAGE (www.jstage.jst.go.jp/browse/hrl). doi: 10.3178/hrl.7.60

\title{
Changes in canopy transpiration due to thinning of a Cryptomeria japonica plantation
}

\author{
Hikaru Komatsu ${ }^{1,2}$, Yoshinori Shinohara ${ }^{3}$, Mari Nogata ${ }^{4}$, Kenji Tsuruta ${ }^{2}$ and Kyoichi Otsuki ${ }^{4}$ \\ ${ }^{I}$ The Hakubi Center for Advanced Research, Kyoto University, Japan \\ ${ }^{2}$ Faculty of Agriculture, Kyoto University, Japan \\ ${ }^{3}$ Faculty of Agriculture, Kyushu University, Japan \\ ${ }^{4}$ Kasuya Research Forest, Kyushu University, Japan
}

\begin{abstract}
:
There is a strong pressing to clarify the effect of thinning coniferous plantations on components of the forest water cycle in Japan. This study evaluates changes in canopy transpiration $(E)$ due to thinning of a Cryptomeria japonica plantation, the most common type of plantation in Japan. Using $E$ derived with the sap-flux method, we modeled canopy conductance $\left(G_{c}\right)$ for periods before thinning and after thinning with the input of the vapor pressure deficit separately. We hypothetically calculated $E$ values using these $G_{c}$ models, respectively, under the same meteorological conditions. The ratio of $E$ estimated using the $G_{c}$ model after thinning to that before thinning was $56 \%$. This value was comparable to the ratio of the total sapwood area for the stand $\left(A_{s}\right)$ before thinning to that after thinning $(63 \%)$. This suggests the possibility of predicting the relative change in $E$ due to thinning using data for the mean diameter at breast height and stem density for the target stand before and after thinning, which are readily available for most $C$. japonica plantations in Japan and are used to predict $A_{s}$.
\end{abstract}

KEYWORDS canopy conductance; Cryptomeria japonica; sap-flux method; sapwood area; thinning; transpiration

\section{INTRODUCTION}

Forests are often situated upstream of urban and agricultural areas, and the water cycle in forested areas affects water resources downstream (Vertessy et al., 2001). The effect of forestry practices (e.g., clearcutting, afforestation, and thinning) on the water cycle of a forest is an important topic in forest hydrology. Numerous studies (e.g., Komatsu et al., 2008a) have examined changes in catchment runoff due to forestry practices. Besides these studies, recent studies (e.g., Forrester et al., 2012) have examined changes in various components of the forest water cycle (e.g., transpiration and interception evaporation) due to forestry practices. Such examinations enhance our understanding of processes underlying changes in catchment runoff.

In Japan, there is a strong need to clarify the effect of thinning on components of the water cycle for coniferous plantations (Komatsu et al., 2007). Coniferous plantations cover approximately $40 \%$ of the forested area in Japan. These plantations need to be thinned twice or three times before they are harvested at an age of $\sim 50$ years. Such thinning has been phased out since 1980 mainly because of an increase in the importation of cheap timbers and woody products from other countries and an increase in employment costs. Several leading researchers in Japan (Tsukamoto, 1998; Kuraji, 2003) pointed out that plantations that have not been thinned could consume more water by evapotranspiration from the dense canopies and reduce catchment runoff and water resources.

Among components of evapotranspiration, several studies (Hattori and Chikaarashi, 1988; Murai and Kumagai, 1989) have examined changes in interception evaporation due to thinning of coniferous plantations in Japan. On the other hand, information on changes in canopy transpiration $(E)$ induced by thinning of coniferous plantations in Japan is quite limited. There has been only one study (Morikawa et al., 1986) that examined changes in $E$ due to thinning. Further, there have been no studies examining changes in $E$ due to thinning of Cryptomeria japonica plantations, although $C$.japonica is the most dominant plantation species.

This study aimed to evaluate changes in $E$ due to thinning of a $C$. japonica plantation. We used data for meteorological factors and $E$ derived using the sap-flux method for two months in growing seasons before thinning and after thinning. As $E$ is the multiplicative product of the sapwood area $\left(A_{S}\right)$ and the mean sap flux per unit sapwood area $\left(J_{S}\right)$ for the stand (Kumagai et al., 2007), the change in $E$ relates to changes in $A_{S}$ and $J_{s}$. Our hypothesis was that the change in $E$ would be primarily due to the change in $A_{s}$, and therefore, the relative change in $E$ due to thinning would be comparable to that in $A_{s}$. We developed this hypothesis on the basis of the results of Kumagai et al.'s (2007) study. Kumagai et al. (2007) examined differences in $E$ between two $C$. japonica stands with different stand structure (i.e., stem density, the diameter at breast height (DBH), and tree height). They reported that the difference in $E$ between stands was primarily due to the difference in $A_{s}$. There are several studies (e.g., Lagergren et al., 2008) reporting relatively small differences in $E$ between thinned and control plots (or before and after thinning) especially for drought periods, because the practice of thinning could relax soil-water competition among trees by reducing interception evaporation and canopy transpiration. This process was not considered in our hypothesis. Soil-water competition is not expected to be severe in Japan, because precipitation is

Correspondence to: Hikaru Komatsu, The Hakubi Center for Advanced Research, Kyoto University, Kyoto 606-8302, Japan. E-mail: kmthkr@gmail.com (C2013, Japan Society of Hydrology and Water Resources. 
generally higher than potential evaporation (Komatsu et al., 2008b).

\section{MATERIALS AND METHODS}

\section{Site description}

We used data for meteorological factors and $E$ obtained at the Yamanokami site. The site is situated $12 \mathrm{~km}$ east of Fukuoka city, Japan $\left(33^{\circ} 38^{\prime} \mathrm{N}, 130^{\circ} 31^{\prime} \mathrm{E}, 100 \mathrm{~m}\right.$ a.s.1.). The mean air temperature, recorded between 1995 and 2005 at a meteorological observatory situated $15 \mathrm{~km}$ from the site, was approximately $17.2^{\circ} \mathrm{C}$. The mean annual precipitation was $1790 \mathrm{~mm}$.

The site was approximately 0.12 hectare in area and located on an east-facing slope of a small hill. The site was covered with $C$. japonica plantations with an age of 39 years in 2010. Surrounding vegetation was broadleaf forest. Thinning was performed uniformly at the site in October 2010. Note that thinning of coniferous plantations in Japan is generally performed during fall-winter. Trees to be cut were selected randomly and pruning of the remaining trees was not performed.

Data on meteorological factors were recorded at a station in an open space situated adjacent to the site (Supplement Text S1). Data for $E$ were recorded at a $10 \mathrm{~m} \times 10 \mathrm{~m}$ plot located in the middle of the slope. Stand structure for the plot before and after thinning is summarized in Table I. The ratio of $A_{s}$ after thinning to that before thinning was $63 \%$. (Measurements of the sapwood area are detailed later in the text.)

\section{Data}

Data for $E$ were determined from sap flux measurements using the thermal dissipation method with Granier-type sensors (Granier, 1987, Supplement Text S2). Sap flux measurements were made for all trees in the plot during August 2010-September 2011. A sensor was inserted, before thinning, on the northern inside of each tree at a depth of 0-20 mm to measure sap flux density $\left(F_{d}\right)$, i.e., radial and circumference variations in $F_{d}$ were not considered in this

Table I. Stand structure of the plot for transpiration measurements

\begin{tabular}{lll}
\hline \multicolumn{1}{c}{ Parameter } & Before thinning After thinning*1 \\
\hline The number of trees & 11 & 6 \\
Stem density $(\mathrm{stems} \mathrm{ha})$ & 1100 & 600 \\
Leaf area index ${ }^{* 2}\left(\mathrm{~m}^{2} \mathrm{~m}^{-2}\right)$ & 4.7 & 2.3 \\
Mean DBH*3 $(\mathrm{cm})$ & $28.9(6.1)^{* 4}$ & $31.6(5.4)$ \\
Total basal area $\left(\mathrm{m}^{2} \mathrm{ha}^{-1}\right)$ & 75.1 & 48.1 \\
Mean tree height $(\mathrm{m})$ & $21.2(1.7)$ & $22.1(1.4)$ \\
Total sapwood area $\left(A_{s}, \mathrm{~m}^{2} \mathrm{ha}^{-1}\right)$ & 22.4 & 14.1 \\
\hline
\end{tabular}

*1 We calculated the mean DBH, total basal area, mean tree height, and total sapwood area after thinning from measurements made on March 3, 2010; i.e., before thinning. We thus assumed that temporal changes in these parameters due to tree growth were negligible. *2 Measured using the plant-canopy analyzer (LI-2000, Li-Cor Inc., Lincoln, Nebraska, USA) on September 28, 2010 and August 31, 2011 (i.e., before and after thinning, respectively).

*3 Diameter at breast height

${ }^{* 4}$ A numeral in the parentheses indicates the standard deviation. study. We aimed to assess changes in $E$ due to thinning relative to $E$ recorded before thinning. This assessment would be possible even when neglecting radial and circumference variations in $F_{d}$ because of the correlation between $F_{d}$ values for different directions/depths for C. japonica trees (Shinohara et al., 2013). Furthermore, the following information could legitimize our experimental design. Consideration of radial and circumference variations in $F_{d}$ is less important than that of tree-to-tree variations for estimating $E$ of a $C$. japonica plantation (Shinohara et al., 2013). $F_{d}$ decreases with depth for $C$. japonica trees (Kumagai et al., 2007) and the sapwood area at a depth of $0-20 \mathrm{~mm}$ for the plot was approximately $80 \%$ of the total sapwood area for the plot.

Using $F_{d}$ data, we estimated $E$ during August-September 2010 and August-September 2011 (i.e., the same months of the year before and after thinning) because we aimed to model canopy conductance $\left(G_{c}\right)$ before and after thinning under similar meteorological conditions. When $F_{d}$ data for a tree were unavailable in a specific period, we filled the data gap using the relationship for $F_{d}$ between the tree and another tree. Using these data, $E$ was estimated as (Kume et al., 2010)

$$
E=\frac{\sum_{i=1}^{n} F_{d_{i}} \cdot a_{S i}}{A_{G}}
$$

where $a_{s}$ is the tree sapwood area, $n$ is the number of the trees included in the plot, and $A_{G}$ is the ground area. $a_{s}$ was determined on the basis of measurements of sapwood thickness. Sapwood thickness was determined for all individuals in the plot using a ruler on a core extracted with a $5-\mathrm{mm}$ increment borer at $1.3 \mathrm{~m}$ above the ground and assessed as the mean of two orthogonal measurements. Distinct color differences were used to identify the boundary between sapwood and heartwood. $a_{s}$ was obtained from the difference between the heartwood area and the stem crosssectional area beneath the bark, where we assumed that the stem cross-sections were circular. In sapwood of $C$. japonica, a "white zone", the water content of which is much lower than that of the heartwood, exists adjacent to the heartwood. There is no water movement in the white zone (Kumagai et al., 2005). The width of the white zone was assumed to be $10 \mathrm{~mm}$, as in Kumagai et al. (2007). The area of the white zone was subtracted from the sapwood area to determine the sapwood area effective for water movement (i.e., $a_{s}$ )

\section{Methods of analysis}

We first calculated and modeled canopy conductance $\left(G_{c}\right)$ with the input of meteorological factors separately for the periods before and after thinning. We then hypothetically calculated $E$ using the $G_{c}$ models before and after thinning under the same meteorological conditions and assessed the change in $E$ due to thinning.

We calculated $G_{c}$ using the simplified Penman-Monteith equation (McNaughton and Black, 1973):

$$
G_{c}=\frac{\gamma \lambda E}{c_{p} \rho D},
$$


where $\gamma$ is the psychrometric constant, $\lambda$ is the latent heat of water vaporization, $c_{p}$ is the specific heat of air, and $\rho$ is the air density. This equation is derived from the PenmanMonteith equation under the assumption of complete coupling between the canopy and atmosphere (see Supplement Text S3). $G_{c}$ was calculated as a daily average conductance using mean daytime $T$ and $D$, and $E$ summed over $24 \mathrm{hr}$ but divided by daylight hours (Phillips and Oren, 1998). $G_{c}$ calculations were made only for days without rain, because $F_{d}$ data could be subject to noise on rainy days (Kumagai et al., 2008).

Using $G_{c}$ data, we developed separate $G_{c}$ models before and after thinning. We assumed that $D$ and solar radiation $(S)$ were the possible factors to be considered in our $G_{c}$ models. As $D$ is generally the most important factor determining $G_{c}$, we regressed the relationship between $D$ and $G_{c}$, on the basis of the least-squares method, to determine the function expressing the effect of $D$ on $G_{c}(f(D))$ (Oren et al., 1999):

$$
f(D)=G_{\text {cref }}(1.00-s \ln (D))
$$

where $G_{c r e f}$ and $s$ express the reference value for $G_{c}$ and the relative sensitivity of $G_{c}$ to $D$, respectively. We used $G_{c}$ data recorded when $S$ was no less than $400 \mathrm{~W} \mathrm{~m}^{-2}$ for this regression, because $G_{c}$ was light-saturated under this condition for $C$. japonica stands examined by Kumagai et al. (2008). We then examined correlation between $S$ and observed $G_{c}$ divided by $f(D)$ to determine whether $S$ needed to be considered.

For the assessment of the change in $E$ due to thinning, we calculated $E$ using $G_{c}$ models separately determined using data before and after thinning. For these hypothetical calculations, we used meteorological data for August and September 2011 as input (Supplement Text S4). We confirmed that our results did not change qualitatively when using meteorological data obtained in August and September 2010 .

\section{RESULTS}

Figure 1 shows time series of meteorological factors and $E$ in August and September 2010 and in August and September 2011. There was frequent precipitation in both years (Figure 1a and 1b). The total $P$ values were 304.0 and $581.5 \mathrm{~mm}$, respectively. $S$ did not show clear temporal trends in either year (Figure 1c and 1d). Day-to-day variations in $S$ generally corresponded to $P$. $T$ tended to be higher in August than in September for both years (Figure 1e and 1f), although a reduction in $T$ was observed in mid-August 2011. Day-to-day variations in $D$ generally corresponded to those in $T$ (Figure $1 \mathrm{~g}$ and $1 \mathrm{~h}$ ). $E$ was higher for 2010 than for 2011 (Figure 1i and 1j). Day-to-day variations in $E$ generally corresponded to those in $D$ in both years. The total $E$ values were 71.0 and $37.3 \mathrm{~mm}$, respectively.

We observed significant $(p<0.01)$ negative $(R=-0.716$ and $R=-0.590$, respectively) correlations between $D$ and $G_{c}$ with $S$ no less than $400 \mathrm{~W} \mathrm{~m}^{-2}$ for 2010 and 2011 according to a two-tailed Pearson's correlation coefficient test (Figure 2). Regressing the relationship between $D$ and $G_{c}$ for $2010, G_{\text {cref }}$ and $s$ for 2010 were determined as $0.00341 \mathrm{~m} \mathrm{~s}^{-1}$ and $0.432 \ln (\mathrm{kPa})^{-1}$, respectively. Similarly,
$G_{\text {cref }}$ and $s$ for 2011 were determined as $0.00190 \mathrm{~m} \mathrm{~s}^{-1}$ and $0.430 \ln (\mathrm{kPa})^{-1}$, respectively. $s$ was nearly the same for the two years, indicating that the difference in $G_{c}$ between 2010 and 2011 for a given meteorological condition was primarily due to the difference in $G_{c r e f}$. The correlation between observed $G_{c}$ divided by $f(D)$ and $S$ was not significant ( $p>$
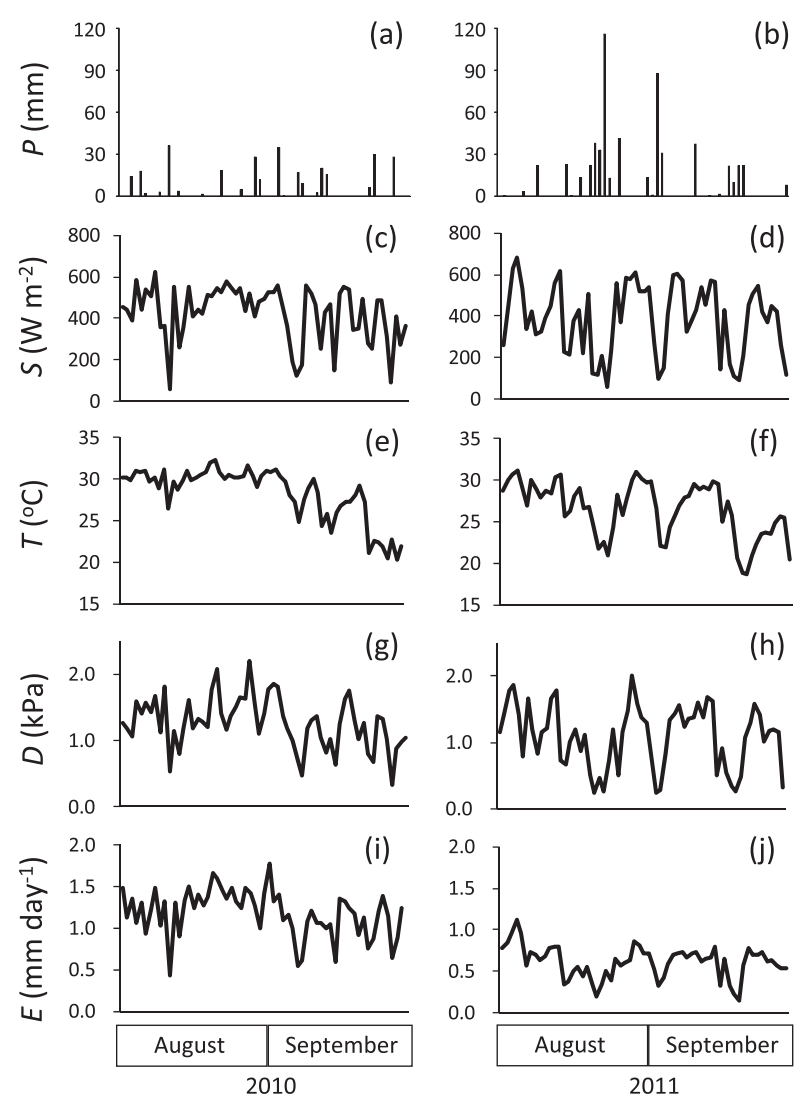

Figure 1. Time series of meteorological factors and canopy transpiration $(E)$; $(\mathrm{a}, \mathrm{b})$ daily precipitation $(P),(\mathrm{c}, \mathrm{d})$ daytimemean (6 a.m.-6 p.m.) solar radiation $(S)$, (e, f) daytimemean temperature $(T),(\mathrm{g}, \mathrm{h})$ daytime-mean vapor pressure deficit (D), and (i, j) daily $E$ for August and September 2010 and for August and September 2011, respectively. Data for $E$ on September 30, 2010 were missing, because data on sap flux density were unavailable on that day for all trees

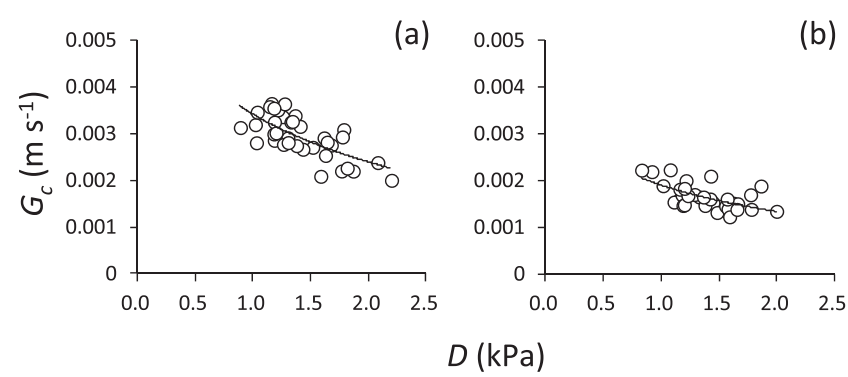

Figure 2. Relationships between vapor pressure deficit $(D)$ and canopy conductance $\left(G_{c}\right)$ with solar radiation no less than $400 \mathrm{~W} \mathrm{~m}^{-2}$ for (a) August and September 2010 and (b) August and September 2011. The solid line is the regression line determined by the least-squares method 
0.10) for either 2010 or 2011 (Figure 3), suggesting that taking $S$ into account did not improve the predictability of $G_{c}$ models developed in this study. Additionally, correlation between observed $G_{c}$ divided by $f(D)$ and the number of successive days with $P$ less than $5 \mathrm{~mm}^{-1}$ day ${ }^{-1}$ before the $G_{c}$ data recorded was not significantly negative $(p>0.10)$, suggesting unimportance of soil water content in determination of $G_{c}$. Thus, $G_{c}$ (in $\mathrm{m} \mathrm{s}^{-1}$ ) for 2010 and 2011 were respectively modeled as (see Supplement Text S5)

$$
G_{c}=0.00341(1.00-0.432 \ln (D))
$$

and

$$
G_{c}=0.00190(1.00-0.430 \ln (D)) .
$$

Figure 4 shows $E$ values calculated using the $G_{c}$ models for 2010 and 2011, respectively, with input of the same meteorological data (i.e., those recorded in August and September 2011). E calculated using the $G_{c}$ model for 2010 was higher than that calculated using the $G_{c}$ model for 2011 throughout the period. The total $E$ was $67.0 \mathrm{~mm}$ for the $G_{c}$ model for 2010 and $37.3 \mathrm{~mm}$ for 2011 . The ratio of the latter

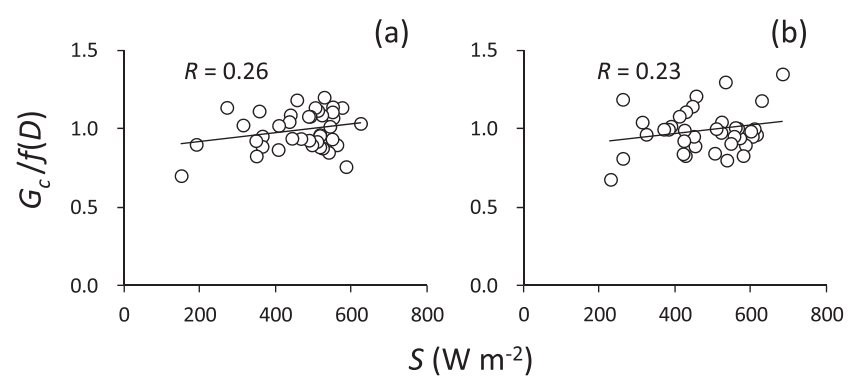

Figure 3. Relationships between solar radiation $(S)$ and observed canopy conductance $\left(G_{c}\right)$ divided by the function expressing the dependency of $G_{c}$ on the vapor pressure deficit (i.e., $f(D)$ ) for (a) August and September 2010 and (b) August and September 2011. Solid lines indicate the regression lines determined by the least-squares method

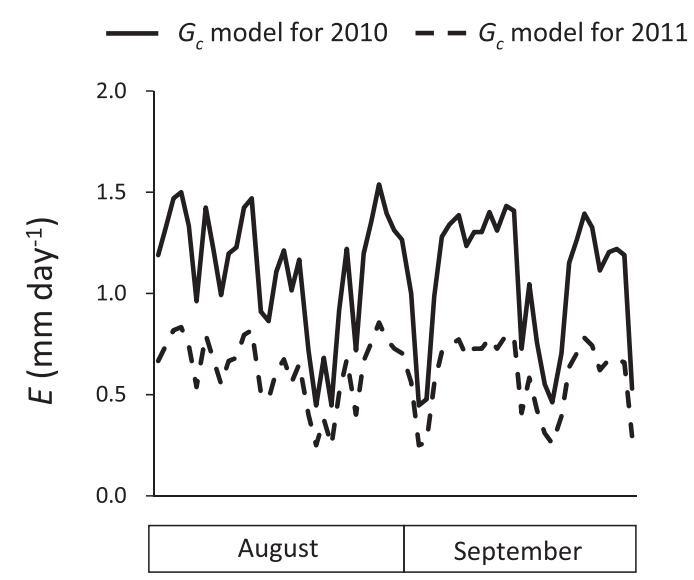

Figure 4. Time series of canopy transpiration $(E)$ calculated with the $G_{c}$ model determined using data for August and September 2010 and August and September 2011. These calculations were made using meteorological data recorded in August and September 2011 relative to the former was $56 \%$. This ratio was comparable to the ratio of $A_{S}$ before thinning to that after thinning (63\%). $E$ for each day determined using the $G_{c}$ model for 2011 strongly correlated with that determined using the $G_{c}$ model for $2010(R>0.99, p<0.01)$, which agrees with the fact that $s$ was nearly the same for 2010 and 2011 .

\section{DISCUSSION}

The relative change in $E$ due to thinning was comparable to that in $A_{S}$ for our case. This is expected on the basis of the assumption that $P$ is generally higher than potential evaporation $\left(E_{p}\right)$ in Japan. The data used in this study indeed satisfy this assumption. The total $E_{p}$ values for August and September 2010 and for August and September 2011 were estimated as 283 and $254 \mathrm{~mm}$, respectively (Supplement Text S6), on the basis of observed meteorological data (Figure 1). The total $P$ values for these periods were 304.0 and $581.5 \mathrm{~mm}$, respectively. Thus, $P$ is higher than $E_{p}$ in both periods.

The assumption of higher $P$ than $E_{p}$ is generally valid in an average year in Japan, implying that our results would be reflective of most cases in Japan. This is supported by the data presented by Morikawa et al. (1986), who carried out another study on changes in $E$ due to thinning for a coniferous plantation in Japan. Morikawa et al. (1986) did not explicitly present $A_{S}$ data for their plot and therefore did not compare the relative change in $E$ with that in $A_{s}$. However, it is possible to estimate $A_{S}$ for their plot using data for the $\mathrm{DBH}$ and stem density (Table 1 of Morikawa et al., 1986) and the relationship between DBH and $a_{s}$ (Figure 1 of Morikawa et al., 1986). $A_{s}$ values before and after thinning are estimated as 23.3 and $17.4 \mathrm{~m}^{2} \mathrm{ha}^{-1}$, respectively. Thus, the relative change in $A_{s}$ is $74 \%$, which is comparable to that in $E(79 \%)$. There are very few studies reporting both changes in $E$ and $A_{S}$ due to thinning of forests not only in Japan but also in other countries. However, the results of Gebauer et al. (2011) examining transpiration at a single-tree scale seem to support our discussion (Supplement Text S7).

It is possible that the assumption of $P$ being higher than $E_{p}$ is not satisfied for specific periods in a low-precipitation year in Japan. The relative change in $E$ due to thinning might be less than that in $A_{s}$ in such cases. Thinning would relax soil-water competition among trees by reducing interception evaporation and canopy transpiration. This results in less significant reduction in transpiration during drought periods for a thinned plot than for a control plot. Several studies (Simonin et al., 2007; Lagergren et al., 2008) have observed such a phenomenon. Simonin et al. (2007) measured $E$ for a pine forest. They reported considerable differences in $E$ between thinned and control plots when soil water content was high. However, the difference was much less when the soil water content was low. Lagergren et al. (2008) conducted measurements in a pine-spruce forest and compared $E$ between thinned and control plots. $E$ for the thinned plot was generally lower than that for the control plot in the first year after thinning. However, $E$ for the thinned plot was rather higher than that for the control plot in the drought period (July-September) of the year when soil water content was low owing to low precipitation. We thus recommend 
further studies examining $E$ for coniferous plantations in Japan before and after thinning using $E$ data recorded in low-precipitation years.

Thinning could improve a light environment in the stand and increase $E$ relative to $A_{S}$ or tree-scale transpiration (Tang et al., 2003). In reality, we did not obtain any evidence of such an increase for our site. This result would not change even when the intensity and/or method of thinning were different from those for this study. We obtained no evidence of an effect of $S$ on $G_{c}$ even for the case before thinning (Figure 3a). This suggests insignificant light competition among trees for our site, because the relationship between $S$ and $G_{c}$ reflects the change in stomatal conductance with $S$, and therefore our results suggest light saturation of stomatal conductance even for the case before thinning. Thus, the improved light environment induced by thinning would not contribute to increasing stomatal conductance for our site. When we analyzed the data at hourly (or halfhourly) time resolution, we might observe evidence of an effect of $S$ on $G_{c}$ (Komatsu et al., 2006). However, this effect is unimportant in determination of $G_{c}$ and $E$ at daily or longer time scales (Figure 3).

Evidence of an effect of $S$ on $G_{c}$ for forests has been reported in previous studies including that made by Kumagai et al. (2008) on C. japonica stands. Thinning might increase $E$ relative to $A_{S}$ or tree-scale transpiration for such cases. However, we presume that this increase would not be considerable. Variations in the relationship between $S$ and $G_{c}$ cause slight differences in $E$ for forests at daily or longer time-scales (Komatsu, 2004). Indeed, most studies examining changes in $E$ due to thinning at these scales did not observe evidence of an increase in $E$ due to the improved light-environment by thinning (Whitehead and Kelliher, 1991; Lagergren et al., 2008).

This study did not attempt to examine gradual changes in $E$ after thinning that might persist for several years. Previous studies for other species (Bréda et al., 1995; Lagergren et al., 2008) reported such gradual changes in $E$ for several years after thinning. Measurement studies at a multi-year scale are required to examine whether such gradual changes in $E$ could occur for $C$. japonica plantations in Japan. Our results have implications for such changes. Water and light competition just after thinning would be less significant than that for the succeeding years. However, the change in $E$ was comparable to that in $A_{s}$, i.e., $J$ did not increase due to thinning, according to data recorded just after thinning. This suggests that $J$ for the succeeding years would be nearly the same as that just after thinning and that the change in $E$ for the years would be caused primarily by the change in $A_{s}$, if meteorological factors for the years did not differ greatly from those for the experimental period of this study.

An increase in leaf area for the succeeding years could cause an increase in $E$. However, the increase in leaf area would accompany an increase in $a_{S}$ and therefore that in $A_{S}$ according to the pipe-model theory (Shinozaki et al., 1964a,b) and observation results for other species (Medhurst and Beadle, 2002). Therefore, an increase in $E$ caused by the increase in leaf area would be regarded as corresponding to the increase in $A_{s}$. Here, we assumed that the relationship between leaf area and $a_{s}$ for an unthinned tree does not change by thinning. Although this assumption is valid for several species (Medhurst and Beadle, 2002), it is unclear whether it is the case for $C$. japonica trees. Further studies examining this uncertainty are required.

It is, at this stage, unclear whether the relative change in $E$ is generally comparable to that in $A_{S}$ for $C$. japonica plantations in Japan. If this is the case, it suggests the possibility of predicting the relative change in $E$ due to thinning on the basis of data for stem density and the mean DBH for a stand before and after thinning. Tsuruta et al. (2011) found a linear relationship between the DBH and $a_{s}$ for C. japonica trees (and a similar relationship for C. obtusa trees). If we input data for the mean DBH and stem density for a stand before and after thinning, we can obtain data for $A_{S}$ before and after thinning of the stand. On the basis of these $A_{S}$ data and the assumption that the relative change in $E$ is equal to that in $A_{s}$, we can predict the relative change in $E$ due to thinning. This method for predicting the relative change in $E$ is practically useful. Data required for the prediction are the mean DBH and stem density. These data are generally available for most $C$. japonica (and also C. obtusa) plantations in Japan. Besides $A_{s}$, the leaf area index (LAI), stem density, and basal area could be used to predict the relative change in $E$ due to thinning (Table I). The use of $A_{s}$ or LAI is more process-based than the use of the stem density or basal area, because $A_{s}$ and LAI directly relate to $E$. The use of $A_{S}$ is more practical than the use of LAI, because the error in $A_{S}$ estimates would be generally less than that in LAI estimates (Tsuruta et al., 2012).

\section{ACKNOWLEDGEMENT}

We acknowledge staff at Kasuya Research Forest, Kyushu University for their thinning practice. Thanks are also due to Dr. Shin'ichi Iida (Forestry and Forest Products Research Institute, Japan) and two anonymous reviewers for providing critical comments. This work is funded by a CREST project (Field and Modeling Studies on the Effect of Forest Devastation on Flooding and Environmental Issues).

\section{SUPPLEMENTS}

Text S1. Measurements of meteorological factors

Text S2. Granier-type sensors

Text S3. Use of the simplified Penman-Monteith equation

Text S4. Interaction between transpiration and meteorological factors

Text S5. Comparison of the model parameters determined

Text S6. Potential evapotranspiration estimates

Text S7. Change in tree-transpiration with thinning

Figure S1. Relationships between the vapor pressure deficit

$(D)$ and canopy transpiration $(E)$

Figure S2. Relationships between the vapor pressure deficit $(D)$ and tree transpiration

\section{REFERENCES}

Bréda N, Granier A, Aussenac G. 1995. Effects of thinning on soil 
and tree water relations, transpiration and growth in an oak forest (Quercus petraea (Matt.) Liebl.). Tree Physiology 15: 295-306. doi: 10.1093/treephys/15.5.295.

Forrester DI, Collopy JJ, Beadle CL, Warren CR, Baker TG. 2012. Effect of thinning, pruning and nitrogen fertiliser application on transpiration, photosynthesis and water-use efficiency in a young Eucalyptus nitens plantation. Forest Ecology and Management 266: 286-300. doi: 10.1016/j.foreco.2011.11.019.

Gebauer R, Volařík D, Urban J, Børja I, Nagy NE, Eldhuset TD, Krokene P. 2011. Effect of thinning on anatomical adaptations of Norway spruce needles. Tree Physiology 31: 1103-1113. doi: 10.1093/treephys/tpr081.

Granier A. 1987. Evaluation of transpiration in a Douglas-fir stand by means of sap flow measurements. Tree Physiology 3: 309320. doi: 10.1093/treephys/3.4.309.

Hattori S, Chikaarashi H. 1988. Effect of thinning on canopy interception in a hinoki stand. Journal of Japanese Forestry Society 70: 529-533.

Komatsu H. 2004. A general method of parameterizing the bigleaf model to predict the dry-canopy evaporation rate of individual coniferous forest stands. Hydrological Processes 18: 3019-3036. doi: 10.1002/hyp.5747.

Komatsu H, Kang Y, Kume T, Yoshifuji N, Hotta N. 2006. Transpiration from a Cryptomeria japonica plantation, part 2: responses of canopy conductance to meteorological factors. Hydrological Processes 20: 1321-1334. doi: 10.1002/ hyp.6094.

Komatsu H, Ide J, Shinohara Y, Haga H, Fujiyama Y, Miyano T, Maruno R, Chiwa M, Kume T, Higashi N, Otsuki K. 2007. Evapotranspiration from unmanaged coniferous plantations. Suiri-Kagaku 297: 107-127.

Komatsu H, Kume T, Otsuki K. 2008a. The effect of converting a native broad-leaved forest to a coniferous plantation forest on annual water yield: a paired-catchment study in northern Japan. Forest Ecology and Management 255: 880-886. doi: 10.1016/j.foreco.2007.10.010.

Komatsu H, Maita E, Otsuki K. 2008b. A model to estimate annual forest evapotranspiration in Japan from mean annual temperature. Journal of Hydrology 348: 330-340. doi: 10.1016/j.jhydrol.2007.10.006.

Kumagai T, Nagasawa H, Mabuchi T, Ohsaki S, Kubota K, Kogi K, Utsumi Y, Koga S, Otsuki K. 2005. Sources of error in estimating stand transpiration using allometric relationships between stem diameter and sapwood area for Cryptomeria japonica and Chamaecyparis obtusa. Forest Ecology and Management 206: 191-195. doi: 10.1016/j.foreco.2004. 10.066

Kumagai T, Aoki S, Shimizu T, Otsuki K. 2007. Sap flow estimates of stand transpiration at two slope positions in a Japanese cedar forest watershed. Tree Physiology 27: 161-168. doi: 10.1093/treephys/27.2.161.

Kumagai T, Tateishi M, Shimizu T, Otsuki K. 2008. Transpiration and canopy conductance at two slope positions in a Japanese cedar forest watershed. Agricultural and Forest Meteorology 148: 1444-1455. doi: 10.1016/j.agrformet.2008.04.010.

Kume T, Tsuruta K, Komatsu H, Kumagai T, Higashi N, Shinohara Y, Otsuki K. 2010. Effects of sample size on sap flux-based stand-scale transpiration estimates. Tree Physiology 30: 129138. doi: 10.1093/treephys/tpp074.

Kuraji K. 2003. Effects of Forests on Stabilizing Streamflow. Nihon Chisan-Chisui Kyokai, Tokyo; 76.

Lagergren F, Lankreijer H, Kučera J, Cienciala E, Mölder M, Lindroth A. 2008. Thinning effects on pine-spruce forest transpiration in central Sweden. Forest Ecology and Management 255: 2312-2323. doi: 10.1016/j.foreco.2007. 12.047 .

McNaughton KG, Black TA. 1973. A study of evapotranspiration from a Douglas fir forest using the energy balance approach. Water Resources Research 9: 1579-1590. doi: 10.1029/ WR009i006p01579.

Medhurst JL, Beadle CL. 2002. Sapwood hydraulic conductivity and leaf area-sapwood area relationships following thinning of a Eucalyptus nitens plantation. Plant, Cell and Environment 25: 1011-1019. doi: 10.1046/j.1365-3040.2002.00880.x.

Morikawa Y, Hattori S, Kiyono Y. 1986. Transpiration of a 31year-old Chamaecyparis obtusa Endl. stand before and after thinning. Tree Physiology 2: 105-114. doi: 10.1093/treephys/ 2.1-2-3.105.

Murai H, Kumagai N. 1989. Studies on effects of some treatments to forest so as to control stream flow in small mountain watershed (III): Influences on hydrological cycle in forest land and runoff and sediment discharge in stream. Bulletin of Shizuoka University Forest 13: 1-25.

Oren R, Sperry JS, Katul GG, Pataki DE, Ewers BE, Phillips N, Schäfer KVR. 1999. Survey and synthesis of intra- and interspecific variation in stomatal sensitivity to vapour pressure deficit. Plant, Cell and Environment 22: 1515-1526. doi: 10.1046/j.1365-3040.1999.00513.x

Phillips N, Oren R. 1998. A comparison of daily representations of canopy conductance based on two conditional time averaging methods and the dependence of daily conductance on environmental factors. Annales des Sciences Forestieres 55: 217-235. doi: 10.1051/forest:19980113.

Shinohara Y, Tsuruta K, Ogura A, Noto F, Komatsu H, Otsuki K, Maruyama T. 2013. Azimuthal and radial variations in sap flux density and effects on stand-scale transpiration estimates in a Japanese cedar forest. Tree Physiology 33: 550-558. doi: 10.1093/treephys/tpt029.

Shinozaki K, Yoda K, Hozumi K, Kira T. 1964a. A quantitative analysis of plant form - the pipe model theory I. Basic analyses. Japanese Journal of Ecology 14: 97-105.

Shinozaki K, Yoda K, Hozumi K, Kira T. 1964b. A quantitative analysis of plant form - the pipe model theory II. Further evidence of the theory and its application in forest ecology. Japanese Journal of Ecology 14: 133-139.

Simonin K, Kolb TE, Montes-Helu M, Koch GW. 2007. The influence of thinning on components of stand water balance in a ponderosa pine forest stand during and after extreme drought. Agricultural and Forest Meteorology 143: 266-276. doi: 10.1016/j.agrformet.2007.01.003.

Tang Z, Chambers JL, Sword MA, Barnett JP. 2002. Seasonal photosynthesis and water relations of juvenile loblolly pine relative to stand density and canopy position. Trees 17: 424430. doi: 10.1007/s00468-003-0256-0.

Tsukamoto Y. 1998. Conservation of Forest, Water, and Soil. Asakura, Tokyo; 138.

Tsuruta K, Komatsu H, Shinohara Y, Kume T, Ichihashi R, Otsuki K. 2011. Allometric equations between stem diameter and sapwood area of Japanese cedar and Japanese cypress for stand transpiration estimates using sap flow measurement. Journal of Japan Society of Hydrology and Water Resources 24: $261-270$.

Tsuruta K, Kume T, Komatsu H, Otsuki K. 2012. Sapwood area and leaf area of Japanese cypress in Kyushu University Forest. Bulletin of the Kyushu University Forests 93: 12-16.

Vertessy RA, Watson FGR, O'Sullivan SK. 2001. Factors determining relations between stand age and catchment water balance in mountain ash forests. Forest Ecology and Management 143: 13-26. doi: 10.1016/S0378-1127(00) 00501-6.

Whitehead D, Kelliher FM. 1991. A canopy water balance model for a Pinus radiata stand before and after thinning. Agricultural and Forest Meteorology 55: 109-126. doi: 10.1016/0168-1923(91)90025-L. 